\title{
Formas de poblamiento en un área rural de Al-Andalus: el valle del río Jandulilla (Jaén)
}

\author{
Tomás Quesada
}

Una de las características esenciales de la sociedad andalusí es la preeminencia de la ciudad como elemento ordenador del conjunto de la sociedad islámica. No obstante, la intensidad de la vida urbana no es una característica exclusiva de esta sociedad, estando presente también en otras sociedades antiguas. Lo que caracteriza a la sociedad islámica sería su homología social, la inexistencia de jerarquías urbanas, y su heterogeneidad topográfica (ACIÉN 1994: pp. 109-II0). Junto con ello, también sería otro rasgo definitorio la radical diferencia entre la vida urbana y el mundo rural ajeno a ella, que puede estar organizado con unas pautas sensiblemente diferentes, pudiendo pervivir aquí elementos de otras formaciones sociales subsidiarias de la islámica (ACIÉN 1994: p. 1 10).

Este lugar central ocupado por la ciudad en la formación social islámica ha llevado, lógicamente, a que el interés de los investigadores de la historia de al-Andalus se circunscriba casi exclusivamente al estudio de éstas desde muy diversos puntos de vista: las jerarquías de poder, el comercio, el derecho, la topografía urbana, etc.; mientras que el medio rural, esencial en toda sociedad preindustrial, del mundo andalusí ha sido objeto de una menor atención, hasta el punto de que $\mathrm{V}$. Lagardère ha llegado a decir recientemente, quizás un tanto exageradamente, que "le paysan d'alAndalus au Moyen Age n'a pas d'histoire" (LAGARDÈRE 1993: p. 9).

Ciertamente, no ha sido hasta los últimos años cuando el estudio del medio rural andalusí ha comenzado a ser considerado como elemento central de las preocupaciones de algunos investigadores', sobre todo en el aspecto del poblamiento rural: su organización, formas de expansión y ocupación del espacio, grupos sociales que lo componen y sus transformaciones a lo largo del tiempo, etc.

Es en esta perspectiva en la que se encuadra este trabajo ${ }^{2}$, fruto de un proyecto de investigación de arqueología extensiva realizado durante los últimos años en la zona meridional de la provincia de Jaén ${ }^{3}$ cuya finalidad era el conocimiento de la red de poblamiento medieval existente en esta zona, alejada tanto

\footnotetext{
I Entre ellos habría que citar, entre otros, a los investigadores asociados a la Casa de Velazquez del C.N.R.S., cuyas investigaciones podemos considerar resumidas en el volumen de BAZZANA, A., CRESSIER, P. y GUICHARD, P. (I988): Les châteaux ruraux d'al-Andalus. Histoire et archéologie des husūunn du sud-est de l'Espagne, Madrid.; y los trabajos de BARCELÓ, M. y sus discípulos sobre la agricultura hidráulica andalusí, entre ellos (1986): Les aigues cercades (Els «qanāt(s)» de l'illa de Mallorca), Palma de Mallorca.; y (1988): Arqueología medieval. En las afueras del medievalismo, Barcelona.

2 Éste tiene su origen en la conferencia pronunciada en el IV Encuentro de Arqueología y Patrimonio, celebrado en Salobreña en octubre de 1993 con el título "Las transformaciones del poblamiento rural islámico durante el siglo XIII. Las montañas subbéticas y los orígenes del reino nașrí de Granada".

3 Este proyecto, titulado "El poblamiento medieval de las sierras subbéticas de Granada y Jaén" se ha desarrollado gracias a la financiación de la Dirección General de Bienes Culturales de la Consejería de Cultura y Medio Ambiente de la Junta de Andalucía a través de su programa de Investigación Arqueológica.
} 
de las grandes ciudades del valle del Guadalquivir como de las del Surco Intrabético y en la que durante toda la Edad Media no se desarrolló ningún tipo de vida urbana, siendo, por tanto, un medio eminentemente rural, donde pudieron pervivir durante más tiempo elementos preislámicos; así como nos interesaba también poder calibrar las relaciones de este medio rural con el mundo urbano y la diversa influencia que a lo largo del tiempo éste tuvo en aquél.

\section{EL MEDIO FÍSICO}

El Sudeste peninsular se caracteriza por la presencia de la montaña, no sólo porque aquí se alcancen algunas de las más altas cumbres de la Península Ibérica, sino también por su extensión, ocupando las zonas altas, de más de 800 m. sobre el nivel del mar la mayor parte del territorio. Son las Cordilleras Béticas, que definen las tierra situadas al Sur del valle del río Guadalquivir. Éstas se dividen en dos grandes grupos, la Cordillera Penibética y la Cordillera Subbética, separadas ambas por una sucesión de depresiones interiores, conocida como Surco Intrabético.

Vamos a centrar nuestro análisis en uno de los conjuntos montañosos que componen la Cordillera Subbética, la comarca conocida actualmente como Sierra Mágina y más concretamente en el valle de uno de los ríos que nacen en ella y que tributa sus aguas al Guadalquivir, el Jandulilla.

Es éste uno de los macizos montañosos con altitudes mayores de esta cordillera, alcanzando varios picos una altitud superior a los $2000 \mathrm{~m}$. (Mágina, Almadén y Cárceles). Geológicamente se trata de un gran afloramiento calcáreo debido al plegamiento alpino rodeado por materiales terciarios, esencialmente margas arcillosas de Keuper. La fragilidad de la roca caliza a la acción del agua y hielo ha permitido la formación de valles y pequeñas depresiones, vegas, que caracterizan, junto con los escarpados picos calcáreos, el paisaje de la zona. También hay que añadir como elementos geológicos característicos el afloramiento en diversos luga- res por la fractura del terreno de rocas evaporitas sedimentadas durante la Era Secundaria dando lugar a la aparición de yesos y sales que contaminan con gran frecuencia las aguas subterráneas haciendo posible la presencia de numerosos cursos de agua salada y paisajes característicos de bad lands. También aparece hierro en vetas muy superficiales, explotadas hasta tiempos recientes.

A pesar, por tanto, de la altitud y de lo agreste del paisaje, los materiales geológicos presentes han hecho posible la configuración de zonas más bajas, los valles de los ríos, que cortan transversalmente la sierra y posibilitan la comunicación entre el valle del Guadalquivir y el Surco Intrabético a través de ellos.

Uno de estos pequeños valles transversales es el del río Jandulilla que separa Sierra Mágina de las Sierras de Cabra y Larva y que permite el contacto entre la zona del Alto Guadalquivir, concretamente la Loma de Ubeda con la Vega de Granada y las hoyas de Guadix-Baza. En la altiplanicie que rodea la Serrezuela de Santerga nace no sólo el río Jandulilla sino también otros ríos que corren en dirección diferente: el Guadahortuna, que discurre hacia el Este a través de una zona de páramos y suaves colinas hasta adentrarse en la Hoya de Baza y verter sus aguas al Guadiana Menor; el Cubillas, que corre en dirección Sur hasta unirse al río Genil en la Vega de Granada; y el río Arbuniel, en dirección Oeste hasta formar, junto con otros pequeños ríos y arroyos el río Guadalbullón, que separa por el Oeste Sierra Mágina de la Sierra de Alta Coloma y que se adentra en la Campiña de Jaén hasta morir en el río Guadalquivir.

Tenemos, por tanto, una compleja red hidrológica que permite unas comunicaciones relativamente fáciles entre diversos puntos del valle del Guadalquivir y Surco Intrabético, las dos zonas donde existen históricamente las mayores y más antiguas concentraciones de población, siendo nuestra zona montañosa, por tanto, a este respecto, una zona marginal pero importante por dos razones, primero por constituir una zona de paso entre ambas y presentar un interés estratégico evidente; y en segundo 
lugar por ofrecer a las poblaciones del valle unas tierras altas, complemento tanto a las actividades agrícolas del valle como la existencia de tierras de pastos necesarias por los rigores del estío en estas latitudes en zonas bajas.

El río Jandulilla nace, como decimos, al Sur de Sierra Mágina, en la altiplanicie de Santerga, y discurre en dirección NE atravesando el macizo de Mágina hasta salir al valle del Guadalquivir en tierras de Jódar. En su camino el río discurre tanto por el piedemonte de la sierra, formado por margas arcillosas, donde ha formado algunas pequeñas vegas, resguardadas por las cumbres y donde un microclima particularmente benigno junto con la presencia abundante de agua, tanto la procedente del río como, esencialmente, la que aflora al contacto de la caliza con las margas, permite la creación de espacios agrícolas muy productivos. Aunque estas áreas de vega son muy variadas, se pueden agrupar en dos grandes zonas, una situada en el curso alto del río, donde se encuentran las de Las Casas, Las Piedras, Huelma, Vadillo de Solera, Grisejo y Cabrita, que hemos denominado a los efectos de este trabajo la Vega de Huelma-Cabrita, con una altitud media de 1000 m.; y una segunda zona, en el curso medio del río, conocida con el nombre de Neblín, con una altitud en torno a los $800 \mathrm{~m}$.

En otras ocasiones, en cambio, el río se abre paso a través de la roca calcárea de la sierra, excavando ahora un valle estrecho y fragoso en el que la roca está muy presente. Así sucede con la zona del Gargantón, que pone punto final a las vegas altas, separándolas de la de Neblín; y, más adelante, en la Sierra Cruzada, que delimita por el Norte la vega de Neblín, y desde donde el río se abre paso ya por la campiña del Guadalquivir.

\section{LOS ANTECEDENTES DEL POBLAMIENTO MEDIEVAL EN EL VALLE DEL JANDULILLA}

Teniendo en cuenta este paisaje, es evidente que en tiempos históricos el poblamiento de este valle se haya concentrado de una forma especial en estas dos áreas de vegas, donde la agricultura puede desarrollarse fácilmente, si bien existe también un poblamiento prehistórico situado en las diversas cuevas y abrigos naturales que ofrece la roca caliza, habiéndose detectado algunos de época neolítica (NAVARRETE 1978: pp. 62-64).

Aunque nuestro trabajo versa sobre el poblamiento medieval de este valle, no es posible comenzar su estudio sin haber analizado, aunque sea someramente, el poblamiento precedente, sobre el que se va a desarrollar el islámico. Así pues, nos parece necesario comenzar por describir los restos de época romana que se encuentran presentes en el paisaje.

En un principio parecería que la presencia romana en esta área montañosa no debería ser excesivamente importante, teniendo en cuenta que las áreas preferidas por éstos, aparte de las costeras, son esencialmente las de los grandes valles, como el Guadalquivir, donde se desarrollaron ciudades romanas de primera importancia como Hispalis, Italica o Corduba; o las grandes depresiones del Surco Intrabético como Illiberis, Acci o Basti, en muchos casos superpuestas a ciudades precedentes de época ibérica.

Pero ya en un primer momento la misma toponimia del territorio, en la que abundan los étimos de origen latino, nos ponía en guardia sobre la presencia romana. En primer lugar, el propio nombre del río: Jandulilla, un diminutivo de Jándula, otro afluente del Guadalquivir, que nos aparece en el siglo X con la grafía Šandula, similar al castellano Sandulam, documentado en el siglo XIII, y que deriva del latino Sanctus lulianus (JIMÉNEZ, QUESADA 1992: p.73). Este nombre debe hacer referencia a un asentamiento íbero-romano situado frente a la desembocadura de este río, ya en la otra orilla del Guadalquivir, el yacimiento conocido actualmente como "Ubeda la Vieja", en un emplazamiento que en el siglo XVIII se conocía con el nombre de "San Julián" (LÓPEZ 1787), que sería el que debió de dar el nombre al río, que la colonización romana debió remontar desde aquí. 
Aparte de éste, hay también otros topónimos de origen latino, si bien algunos arabizados como el anterior. Así, podemos considerar el de Jódar y el del yacimiento romano de Sótar, derivados del latino saltus, a través del vulgar sautus, el primero de ellos arabizado, convirtiendo la /s/ latina en šim árabe, y éste en /j/ castellana; y el segundo apenas evolucionado. En las cercanías de este último encontramos también los topónimos de Solera y Polera, derivados de dos adjetivos latinos, solarius y polarius, que hacen referencia a su situación topográfica, al Sur y al Norte respectivamente el uno del otro. Igualmente son también de origen latino otros topónimos del valle como Neblín o Chincóyar, dos castillos conquistados por los castellanos en el siglo XIII (JIMÉNEZ, QUESADA 1992: pp. 54,63 y 68). $O$, más allá del valle del Jandulilla, el río Guadahortuna, híbrido árabo latino: "Wādī Furtūnā", o el Muntšāair de los siglos IX-X, derivado del latino "Montem Sacer" (SECO DE LUCENA 1974: pp. 62-63).

Estos datos previos nos hacían suponer que la presencia romana debió ser importante, y la prospección arqueológica así nos lo confirmó. Tanto en la vega de Neblín como en la de Huelma-Cabrita hay presencia de vestigios arqueológicos de época romana.

En la Vega de Neblín se encuentran dos yacimientos en los que hay restos de época romana: el del "Barranco de las Majadas" y el del "Barranco de Rincón", en los que aparece terra sigillata romana. $Y$ en la Vega de Cabrita también encontramos poblamiento íbero-romano: en primer lugar el importante yacimiento del "Cortijo del Pajarillo"; y cercano a este yacimiento, en el llamado "Barranco de Sótar", se encuentra otro que aporta esencialmente cerámica romana. Más arriba aún, en el curso alto del río, en torno a Huelma y a la cadena de cerros que separan el valle del Jandulilla del nacimiento de los ríos Arbuniel y Guadahortuna aparecen también yacimientos de época romana: el del "Cortijo de las Casas", en la vega más alta del Jandulilla, cerca del nacimiento de este río; un poco más abajo, en las inmediaciones del casco urbano de Huelma, se encuentra el yacimiento del "Cerrillo de las Rojas", de donde procede una lápida sepulcral que data de finales del siglo I de n. e.,,$y$ también algunas monedas bajoimperiales. $Y$ ya en la cabecera del Jandulilla, en la divisoria de aguas de los diferentes ríos, encontramos el yacimiento de "Cantaruelas", donde accidentalmente aparecieron unas sepulturas romanas, junto con algunas monedas bajoimperiales y abundante cerámica, terra sigillata tanto hispánica como africana clara; y cerca de este yacimiento, en el "Barranco de la Culebra", se halla el yacimiento de la "Fuente de la Peña", donde se conserva aún un acueducto de origen romano junto a un yacimiento con abundante terra sigillata (QUESADA, MOTOS e.p. I, 2, 3).

Si bien los primeros yacimientos que hemos citado, los situados en las vegas del río, podemos considerarlos por su emplazamiento como asentamientos agrícolas, quizás villae bajoimperiales, los restos de los últimos que hemos citado nos hablan de unos asentamientos que, aparentemente al menos, superan las simples actividades agrarias, pudiéndose pensar quizá que puedan estar relacionados con el no localizado municipium romano de Vergilia, tal y como se puede desprender de la lápida del yacimiento de "Cerrillo de las Rojas" alusiva al ordo verghiensium. Por su parte el yacimiento de "Cantaruelas" se podría relacionar más que con una explotación agrícola con la actividad minera, al encontrarse en una zona donde abunda el mineral de hierro, que ha sido explotado en minas tradicionales hasta tiempos recientes. Y, finalmente, el yacimiento de Fuente de la Peña, ubicado en un punto donde se cruzan los caminos que conducen a los diferentes ríos existentes en la zona, Jandulilla, Arbuniel, Cubillas y Guadahortuna, habría que ponerlo en relación con el control de las vías de comunicación.

\footnotetext{
4 En la lápida, algo deteriorada, que al parecer formaba parte de un monumento funerario que no se ha conservado, se puede leer «...VIR HISPANVS ANNOR VI PIOS IN SVOS HIC SITVS EST STTL HVIC ORDO VERGHIENSIVM LOCVM SEPVL... PEMSAM FVNERIS DECREVIT». Agradezco muy sinceramente al catedrático de Historia Antigua de la Universidad de Granada, profesor Dr. Cristóbal González Román la lectura de la misma así como su datación.
} 
Así pues, de los datos que nos ofrece la prospección arqueológica, que deberían ser confirmados con excavaciones en profundidad o sondeos estratigráficos, podemos pensar en la presencia romana en estas tierras con una finalidad agrícola en las vegas del río y explotando las riquezas minerales y controlando las vías de comunicación en la cabecera del mismo, en una lógica de dominio del territorio plausible con los intereses colonizadores de los romanos.

\section{EL POBLAMIENTO ALTOMEDIEVAL}

Aparte de los testimonios de época romana, encontramos también en alguno de los yacimientos que hemos visto hasta ahora elementos posteriores, altomedievales, especialmente significativo sería el caso del de "Cantaruelas", cuyo arco cronológico puede prolongarse incluso hasta el siglo $\mathrm{Vl}^{5}$.

Aparte de este yacimiento hemos encontrado también materiales altomedievales en otros yacimientos, de los cuales dos son claramente no fortificados, el de "Hornillos Bajos" en la ladera que asciende hacia la Sierra de la Cruz, en la Vega de Neblín; y el de "Majada de las Vacas" en la Vega de Huelma, cercano al yacimiento romano de "Cerrillo de las Rojas"; y otros tres que se encuentran en la cima de sendos cerros y que bien pudieran haber servido de refugio, aunque sólo en uno de ellos se aprecian hoy día vestigios de actividad constructiva. Se trata de los yacimientos de "Cerro Gonzalo", situado en el margen de la vega de Huelma-Cabrita, sobre las mismas fuentes del río Jandulilla, en el "Puerto de los Gallardos" a 1255 m. de altura; el del "Castellón de la Cañada del Acero", que asciende ya hacia el interior de Sierra Mágina, a I 80 m.; y, finalmente el de "Dientes de la Vieja", situado en un promontorio rocoso en la divisoria de aguas entre el río Jandulilla y el Guadahortuna, a una altura de II 44 m., que presenta restos muy enrasados de diversos muros y materiales constructivos.

En todos estos yacimientos aparece cerámica altomedieval, realizada a mano y torneta, abundando, en cuanto a formas, las marmitas, redomas y tinajas con decoración de cordones; y en alguno de ellos aparece también cerámica ya claramente califal como verde y manganeso sobre engalba blanca o bajo cubierta vítrea melada, como cerámica más tardía.

La cronología de estos yacimientos nos llevaría a considerar una extensión máxima de su período de ocupación hasta el siglo $X$, siendo buena muestra de los "yacimientos de altura" propios de la primera época de ocupación islámica de la Península, la de la formación de al-Andalus.

Según todos los indicios durante esta época (siglos VIII-X) la población indígena, aprovechando la fractura del Estado visigodo provocado por la conquista musulmana, intensificaría el proceso de huida a los montes, iniciado ya en el Bajo Imperio (WICKHAM 1984: p. 30). Es éste un proceso que habría llevado a diversas comunidades campesinas, sobre todo a las situadas en los márgenes del territorio efectivamente dominado por los visigodos ${ }^{6}$, a constituirse de forma autónoma, produciéndose en algunos casos su vuelta a formas de organización social prerromanas.

Sobre estas comunidades, ya en el siglo IX, una vez que el Estado islámico se ha consolidado en las zonas centrales, socialmente hablando, de al-Andalus, comenzarían los emi-

\footnotetext{
5 La cronología y otras características sobre esta cerámica romana tardía me han sido proporcionadas por la profesora de arqueología clásica dra. Margarita Orfila Pons, lo que le agradezco sinceramente.

6 No hay que olvidar que el Estado visigodo aparece como el principal heredero del mundo romano en la Península, con cuya aristocracia se entronca y que dominaría de forma más efectiva las grandes zonas romanizadas, en nuestro caso el valle del Guadalquivir y Surco Intrabético. La progresiva disolución de este Estado en el siglo VII especialmente habría facilitado a estas comunidades montañesas su progresivo alejamiento social y distanciamento tributario de la sociedad hispano-visigoda, constituyendo comunidades más apegadas al saltus y alienadas de los modos predominantes en la formación social visigoda, QUESADA, T. (199I): "El poblamiento medieval en las sierras subbéticas de Jaén y Granada. El caso de Sierra Mágina" Studia Historica. Historia Medieval IX pp. 163-167; también OLMO ENCISO, L. (1992): "El reino visigodo de Toledo y los territorios bizantinos. Datos sobre la heterogeneidad de la Península Ibérica". Coloquio hispano-italiano de Arqueología Medieval, Granada, pp. 185 -1987.
} 
res cordobeses a ejercer una presión creciente tendente a su islamización e integración social en el Estado andalusí, fruto de la cual sería la presencia en alguno de estos yacimientos, y en algunos otros de nueva aparición, de cerámica claramente califal.

Junto a estos yacimientos cuyo momento final habría que situarlo en los siglos X-XI, encontramos otros en los que la cerámica más antigua que se encuentra en ellos se corresponde precisamente con la más tardía de los anteriores y que, parcialmente, coinciden en su emplazamiento con alguno de los yacimientos romanos reseñados más arriba, como es el caso del "Barranco de las Majadas" y "Barranco de Rincón" en la vega de Neblín y los de "Cortijo de las Casas" o "Cortijo Pajarillos" en la de Cabrita-Huelma; o bien se encuentran en las inmediaciones de ellos, en todo caso en los dos conjuntos de vegas de que venimos hablando: en Neblín aparece cerámica de este período en el yacimiento de "Hornillos Bajos" y en el de las "Cuevas de Neblín"; y en la de Cabrita-Huelma en los de "Cortijo de las Piedras", "Cortijo de la Castellanía" y "Cortijo de los Nacimientos".

De todos los yacimientos prospectados que presentan cerámica califal o inmediatamente posterior ninguno presenta evidencias de fortificación, siendo consecuencia, probablemente, de la actuación de cAbd al-Raḥmān III contra ellos, que acabaría con la sustitución, - la reorganización, del poblamiento altomedieval, como recoge explícitamente Ibn Hayyān cuando dice, tras la victoria definitiva del califa sobre los rebeldes de estas montañas: "...encargó destruir las mayores -fortificaciones- con sus alcazabas, construidas en época de desidia, ya que eran refugio de disidencia e hipocresía, cuya permanencia le parecía dañina para la gente leal y recta. El recorrió la mayoría, imponiéndose a aquella gente y haciéndoles rendir sus atalayas: hizo general la destrucción de tales fortalezas, haciendo descender a sus moradores al llano y obligándolos a la obediencia..." (IBN HAYYĀN 1981: p. 154).

La actuación del califa cordobés supuso, entonces, un cambio en el poblamiento. El existente hasta ese momento, el altomedieval, debió ser, probablemente, un hábitat disperso y, con unas fortificaciones que, a pesar de su abundancia, -Ibn Hayyān dice que sólo uno de los rebeldes de estas montañas, Ibn al-Šāliya poseía más de un centenar- ${ }^{8}$, no debieron ser tan sólidas ni contar con tantos elementos constructivos como en un principio podríamos pensar. Así pues, hemos de pensar que al menos parte de las numerosas fortificaciones en poder de los rebeldes muladíes no debieron ser más que simples refugios rocosos sin apenas o ninguna obra de fortificación, lo que, evidentemente, hace muy difícil hoy día su localización.

Aparte de estos pocos datos ofrecidos por la arqueología tenemos también de este período noticias procedentes de las fuentes escritas, especialmente del ya mencionado lbn Hayyān, quien nos transmite la idea de una montaña poblada y fortificada. Del relato que hace éste y otros autores árabes de las diversas campañas y sucesos acaecidos en la sierra se puede deducir que la influencia de la sociedad islámica en la montaña hasta entonces había sido muy escasa, incluso en el aspecto religioso, perdurando aún población mozárabe, tal y como refleja un poema de 'Abd Rabbihi con motivo de las victorias de anNāṣir en Jaén: "Dejaste en las dos guardas de Jaén -Muntilūn y Šumuntān- una carnicería, que ha hecho llorar a renegados en tierras politeístas". Aunque, desde luego, en este momento es ya predominante la población muladí, indicio de lo cual es el hecho de que la práctica totalidad de los rebeldes que se

\footnotetext{
7 La resistencia a esta integración islámica estaría en la base de la fitna del siglo IX, uno de cuyos máximos exponentes sería la revuelta del famoso Umar ibn Hafsūn, (ACIÉN 1994).

8 “...cediendo todas sus fortalezas y baluartes en Somontín, que eran cerca del centenar, castillos algunos famosos por su inexpugnabilidad", IBN HAYYĀN: p. 154.

9 Una crónica anónima de `Abd al-Raḥmān III al-Nāșir, ed. y trad. de LÉVI-PROVENÇAL, E. y GARCÍA GÓMEZ, E. Madrid-Granada, 1950, p. 104.
} 
mencionan lo son. Junto a la población autóctona, la presencia de elementos árabes es prácticamente nula: sólo encontramos población árabe, como era de esperar, en el único núcleo urbano de las inmediaciones, Mantišsa, donde se asentaron 'Uqaylíes, y Asadíes en el contiguo Wādì 'Abd Allāh; y en el otro núcleo con pretensiones urbanas en los primeros tiempos de al-Andalus, Jódar, donde se asentaron Kilābíes descendientes de al-Șumayl (AGUIRRE, JIMÉNEZ 1979: p. 105), aunque ya en el siglo IX se subleva en este lugar un muladí, Jayr b. Šakir, mientras que en Mantǐ̌sa son aún los Uqaylíes quienes se fortifican en estas fechas.

El elemento indígena, sea éste mozárabe o muladí, es prácticamente el único elemento poblacional existente en la montaña. En corroboración de esta afirmación podemos traer a colación la toponimia, que es en su práctica totalidad preárabe, sobre todo la citada en las fuentes árabes de los siglos IX$X$. Así junto al Šawdar que ya hemos comentado, encontramos Mūnt Šāqir, con la característica de contener el elemento "mont-" que hace referencia en estos primeros tiempos a una población mozárabe/muladí (ACIÉN 1993: p. 165). En las cercanías, aunque no citados expresamente en las fuentes escritas de este período, encontramos asimismo el río Guadahortuna, topónimo híbrido árabo-latino: "Wādī" "Furtuna", o Santerga, posiblemente un hagiotopónimo antiguo'. También en el Muqtabis de Ibn Hayyān encontramos otros topónimos y hagiotopónimos latinos que se pueden adscribir a esta zona de las montañas del sur giennense, entre ellos podemos citar como ejemplo los de Muntilūn, Šumuntān, Margìța, Šant Aštabīn y Mūrīna (IBN HAYYĀN 198I).

En definitiva, según los datos de que disponemos, podemos aventurar que existió si no una continuidad en el modelo de poblamiento, sí al menos en la ocupación del territorio puesta en evidencia por la pervivencia de numerosos topónimos preárabes hasta los siglos X-Xl y por la presencia en los mismos yacimientos de cerámica romana junto con otra musulmana de época califal e inmediatamente posterior. Tanto los datos arqueológicos como los toponímicos nos llevan, por ende, a considerar que si bien la red de alquerías fue organizada en los siglos X-XI, una vez que la sociedad islámica llega a la montaña y la organiza según sus intereses y necesidades, la estructuración del espacio en su conjunto puede deberse a una "herencia" preislámica, fruto de una realidad preexistente (BAZZANA, CRESSIER, GUICHARD 1988: pp. 296-297).

\section{EL POBLAMIENTO ANDALUSí (SIGLOS X/XI-XIII)}

Con el triunfo de la islamización que suponen los éxitos de 'Abd al-Rahmān III se constituye el que podríamos llamar en sentido estricto el poblamiento andalusí, que abarcaría el período comprendido entre los siglos XI y XIII, fecha en la que la conquista cristiana inaugurará un nuevo modelo de poblamiento.

Intentaremos abordar el poblamiento islámico existente hasta el siglo XIII en el valle del río Jandulilla tomando como punto de partida las noticias que nos transmiten los castellanos cuando en el transcurso de sus conquistas llegan hasta estas tierras en el segundo cuarto de este siglo. La primera instalación cristiana permanente data de 1227, cuando se produce la conquista de Jódar. Desde este castillo, situado en los primeros contrafuertes del frente externo de las Subbéticas, se inició en los años siguientes la conquista de los tramos alto y medio del valle por obra del señor de Jódar don Sancho Martínez. Hasta mediados de siglo consiguió hacerse con el control de diversos castillos y otros poblados no fortificados. Según los datos que nos aportan diversos documentos en torno a 1240- I 250 había conquistado los castella, según la nomenclatura de los documentos, de Chincóyar y

10 J.M. Piel, "Os nomes dos santos tradicionais hispânicos na toponimia peninsular", Biblos XXV (1949) 287-353 y XXVI (I950) 28|-3|4. La derivación del genitivo denotaría, según este autor, su antigüedad (vid. especialmente p. 288). 
Neblir" y una serie de poblados relacionados con ellos, concretamente en un documento de 1255 se citan los de Solera, Polera, Gris, Alló y Ogáyar'2. Aparte de ellos también aparecen en otros documentos de la época los castella de Bélmez, Huelma y Cabra'3. No son éstos, desde luego, los únicos existentes ya que la prospección arqueológica nos ha proporcionado restos constructivos y cerámicos de otros muchos yacimientos islámicos, tanto fortificados como no, como veremos más adelante.

No obstante su parcialidad, estos datos proporcionados por las fuentes escritas nos ponen sobre la pista del tipo de poblamiento existente en el momento en el que los feudales se imponen a él. Según ellos, los dos tipos fundamentales de asentamientos humanos existentes en la zona son los castella y los logares. Y, efectivamente, éstos, fortificaciones y poblados, son los dos únicos elementos poblacionales que hemos podido detectar, no sólo documentalmente sino también arqueológicamente.

El primer elemento de ellos, el castellum podemos ponerlo en relación con el hịiṣn musulmán, según la definición de "castillo rural", caracterizado por su función de refugio, en unas ocasiones simplemente temporal y en otras albergando en su interior un pequeño hábitat permanente (BAZZANA, CRESSIER, GUICHARD 1988: p. 293).

Conocemos varios yacimientos que pueden corresponder a este tipo. Se trata en todos los casos de castillejos de planta poligonal construidos en tapial y/o en mampostería, que ofrecen una cerámica bastante homogénea, compuesta esencialmente de ataifores vidriados en tonos verdes y frecuentemente con decoración estampilla bajo la cubierta vítrea; jarros y jarras pintadas, bien con óxido de hierro o de manganeso, y algunas esgrafiadas, y tinajas estampilladas. Es un ajuar cerámico adscribible esencialmente al siglo XII y comienzos del XIII, correspondiéndose por tanto cronológicamente con los que fueron conquistados por don Sancho Martínez en estos mismos años. Son concretamente cinco los yacimientos que responden a estas características, situados tres de ellos en el valle del río Jandulilla, y otros dos situados a oriente, el denominado "Tejar de los Moros", en Larva y el del "Cerro San Juan" en Cabra. Y ya en el valle del Jandulilla, en la vega de Neblín, encontramos el denominado "Castillejo de Neblín"; en la de Cabrita-Huelma el "Castillazo" de Ruicerezo; y a medio camino entre ambas vegas el "Castillejo" del "Barranco de Aguas Amarguillas".

El segundo elemento, los logares, deben corresponder a las qurà, las alquerías, que podríamos definir como comunidades rurales libres y propietarias de la mayor parte de las tierras, dotadas de sus propios mecanismos internos de organización (LAGARDÈRE 1993: p. 86). Arqueológicamente estos emplazamientos son más difíciles de detectar debido, por una parte, a su menor consistencia física, siendo sus restos arquitectónicos mucho más deleznables que los de las fortificaciones. La cerámica en superficie es en estos casos prácticamente el único resto arqueológico observable, al que se añade en ocasiones la existencia de algunos aljibes y restos muy deteriorados de algún muro.

A este período cronológico, siglos XII-XIII, y por lo tanto susceptibles de ser relacionados con los logares citados en la documentación castellana del momento, encontramos diversos yacimientos que no presentan, al menos de forma clara, indicios de fortificación. Son los del "Castil" de la Sierra de la Cruz y "Cerro de la Atalaya", en la Vega de Neblín; y

\footnotetext{
II Privilegio rodado de Fernando III fechado el 6 de abril de 1243 en Valladolid, publ. por HIGUERAS MALDONADO, J. (I974): Documentos latinos del siglo XIII al XVII en los archivos de Baeza (Jaén). Transcripción, traducción y comentario lingüístico, Jaén, pp. 22-24.

12 Documento fechado el 26 de agosto de 1255, publicado por SEGURA MORENO, M. (1976): Estudio del Códice Gótico (siglo XIII) de la Catedral de Jaén, Jaén, pp. 192-193.

13 Los castella de Huelma y Bélmez aparecen citados también en el documento de I243, v. nota 26. Y Cabra en un documento fechado el 20 de febrero de 1254, GONZÁLEZ JIMÉNEZ, M. (ed.) (I99I): Diplomatario andaluz de Alfonso X, Sevilla, pp. I08-II0.
} 
los del "Cortijo de la Castellanía", "Los Nacimientos", "Cortijo Manzanares", "Cerro de la Encina" y "Cortijo de las Piedras", en la Vega de Cabrita-Huelma, en los que aparecen restos cerámicos de este período y en algunos de ellos además restos de muros (Castil de la Sierra de la Cruz, Cortijo de las Casas y Cerro de la Atalaya) y/o aljibes (Cerro de la Atalaya y Cortijo de la Castellanía). En todos ellos aparece cerámica similar a la encontrada en los yacimientos fortificados que hemos citado anteriormente.

Así pues, tanto las noticias que los cristianos nos dan del territorio que conquistan como los datos aportados por el registro arqueológico son coincidentes en definir el poblamiento de la sierra en el siglo XIII: una serie de castillos en torno a los cuales se encuentran otros poblados no fortificados, asociados presumiblemente a los primeros. Es éste un modelo de poblamiento que en sus rasgos básicos responde a las características del analizado para otras zonas de alAndalus para esta época, en especial el de Šarq al-Andalus, basado también en la conjunción de estos dos elementos, el hišn y la qaryà (BAZZANA, CRESSIER, GUICHARD 1988: pp. 259-292).

A todos estos yacimientos habría que añadir los existentes ya en época califal, mencionados más arriba, y que perduran también durante este período. Por tanto, tendríamos unos núcleos de poblamiento rural de los siglos $\mathrm{X}-\mathrm{Xl}$, a los que posteriormente vinieron a añadirse otros, nuevas alquerías asociadas a las fortificaciones que aparecen ahora en el territorio. Estos castillejos parecen deberse a un momento posterior al de la creación, o reorganización, del poblamiento rural llevado a cabo en época califal. La factura de los mismos, su planta, técnicas constructivas, etc., nos llevan a una cronología posterior a la califal, ya que presentan características propias de los modelos constructivos desarrollados a partir de los siglos XI-XII. Abundando en este sentido, como hemos visto más arriba, la cerámica que se encuentra en estos yacimientos es claramente posterior a la de los del grupo anterior (algunos de los cuales presentan también, evidentemente, este tipo de cerámica, puesto que aunque anteriores en su origen, fueron coetáneos de estas fortificaciones): aquí no aparece ya el verde y manganeso ni otras cerámicas típicas del siglo XI, sino otras adscribibles a los siglos XII-XIII fundamentalmente.

La aparición después de la época califal de estos castillos y poblados debe estar en relación con la aparición de una toponimia más claramente árabe en la zona. Toponimia que debió aparecer entre los siglos XI y XIII, puesto que está ausente en el período anterior, no apareciendo en las crónicas de época califal, como hemos podido ver más arriba, mientras que los cristianos la encuentran ya en el siglo XIII. Siguiendo en el valle del Jandulilla y sus aledaños, encontramos ahora Bedmar, que aparece por primera vez en el siglo XI citado en las Memorias del rey 'Abd Allāh (GARCÍA GÓMEZ, LEVÍ PROVENÇAL 1980: p. 16I), del árabe "al-Mațmar" con un significado de "silo" y, por extensión "cueva" (TERES 1972: p. 331-332); Bélmez, una metátesis de la raíz "l.b.s.", que tendría un significado de "lugar protegido" (JIMÉNEZ, QUESADA 1992: p. 62); Huelma, "Walda(t) al-mā'", habiendo perdido la /d/ intervocálica, significando "nacimiento de agua" (IIMÉNEZ, QUESADA 1992: p. 61); o Larva, "al-carbicā"', "el miércoles". Pudiendo incluso en el caso de Huelma apuntarse la existencia de una homonimia con el "Guelma" argelino o el "Guelmes" marroquí. Ambas son poblaciones situadas en la montaña y caracterizadas por la abundancia y calidad de sus aguas, al igual que la localidad giennense.

Cabe, si admitimos esta homonimia, la posibilidad de que Huelma se trate de un asentamiento beréber que reprodujese el nombre del lugar de origen de sus fundadores. Podríamos pensar, entonces, en la existencia de unos asentamientos beréberes producidos tras la desaparición del califato, cuando se abre en estas montañas un período de ininterrumpido dominio beréber, puesto que a las dominaciones almorávide y almohade en todo alAndalus, hay que añadir aquí la precedente del reino șinhāŷa de los ziríes granadinos. 
No estamos en condiciones de poder atribuir concretamente a qué grupo pudo deberse esta inmigración, que se plasmó en la construcción de estos castillejos en las mismas zonas donde ya se encontraba organizado un poblamiento rural de alquerías.

La aparición de este conjunto de fortificaciones transforma, añadiéndole un elemento nuevo, las fortificaciones, al poblamiento de la montaña, puesto que provoca cambios en la anterior vinculación del territorio con las ciudades del valle, lo que nos introduce en uno de los grandes problemas a analizar: la relación del poblamiento rural de la sierra con el mundo urbano del valle.

Una de las características principales del poblamiento rural de la montaña es la ausencia de ciudades y vida urbana. En toda la sierra no existe ninguna madina, lo que, evidentemente, no es una característica peculiar de esta sierra en concreto, sino que igual situación se reproduce en muchas otras zonas montañosas. Y no sólo no existen ciudades, sino que al parecer la influencia del mundo urbano es bien escasa.

La presencia urbana fue, realmente, siempre muy escasa en la montaña. Aparte de la probable existencia de un municipium stipendiarium en época romana, al que hace alusión la lápida funeraria que ya hemos comentado, sólo encontramos en las inmediaciones de la sierra la ciudad hispano-romano-goda de Mentesa, aún existente en la primera etapa andalusí con el nombre de Mantî̌sa, aunque ya en declive en el siglo $X$; y Jódar, que al parecer tuvo un cierto auge $y$ unas características quasi urbanas en los siglos IX-X. De todos modos, estos dos núcleos no se encuentran en la sierra, sino en los márgenes del valle del Guadalquivir.

Posteriormente surge un sistema de alquerías que durante la época califal debió estar regido por el gobernador de la kura de Ŷayyān, momento en el que la relación entre el poblamiento rural de la montaña y el urbano del valle debió ser más intenso. Pero una vez desaparecido el califato y deshecha la antigua kura de Ŷayyān tanto territorial como administrativamente entre los diferentes reinos taifas de Granada, Toledo y Sevilla, la aparición de las fortificaciones que hemos comentado más arriba debió responder a la necesidad de controlar el territorio de otra manera, una vez que el control administrativo y político urbano había desaparecido. De ahí que en cada una de las dos zonas donde se concentra el poblamiento se ubique una fortificación: en Neblín el castillo de Neblín y en Cabrita-Huelma el de Ruicerezo; igualmente se instalan otras en lugares de significación comercial, Larva, topónimo que hace alusión inequívoca a un mercado hebdomadario, o puntos estratégicos en las comunicaciones con Granada, como Cabra, en cuyas inmediaciones se bifurcaban los caminos que conducen desde el valle del Guadalquivir hacia Granada y Guadix'14; y el "Castillejo" del Barranco de Aguas Amarguillas, quizás el Chincóyar de los documentos, situado a medio camino entre las vegas de Neblín y Cabrita y que serviría de nexo de unión entre ambas. Estas fortificaciones aparecen, pues, regulando tanto la vida agrícola de las comunidades asentadas en las vegas como las actividades comerciales y las vías de comunicación. Es decir, pone en marcha un modelo de poblamiento autónomo, ajeno al ámbito de influencia de las ciudades del valle.

Si bien podemos llegar a esta conclusión general, quedan aún por dilucidar otras importantes cuestiones, tales como precisar las formas y modos cómo estos "castillos rurales" y su sistema de alquerías se relacionaban tanto entre sí como con otras instancias exteriores, especialmente con los centros del poder político de al-Andalus, que aún no podemos precisar con el suficiente detalle.

\footnotetext{
14 En este sentido podemos leer en Madoz lo siguiente: "En estos montes colocados a la izq. del Guadiana, se encuentran los caminos siguientes: el que desde Jodar va a la Venta del Vidrio y de alli a Cabra del Santo Cristo, subdividiéndose en dos, media leg. por bajo de dicha v., de los cuales el de la der. conduce á Guadix por la Alamedilla, y el de la der. á Granada por Guadaortuna", MADOZ, P. (1988): Diccionario Geográfico-Estadístico-Histórico de España y sus posesiones de Ultramar, Madrid, I845-I850, sub voce «Jaén, prov.», reimp. facsímil ed. Ámbito, vol. Jaén, Salamanca, , pág. III.
} 
Esta situación de autonomía de la montaña con respecto al valle debió de ser la que encontraron los cristianos cuando en el curso de su expansión lleguen a estas tierras a lo largo del siglo XIII. Podemos calibrar el grado de relación entre la montaña y la ciudad en el siglo XIII analizando el sistema de conquista que siguen los castellanos. Aunque las noticias que tenemos no son abundantes, los datos que podemos extraer de la documentación pueden proporcionarnos algunas pistas. Sabemos que Fernando III pactó con Muhāmmad al-Baŷyasí, rey de Baeza, y fruto de estas relaciones fue la entrega de Andújar y la conquista de Baeza, dos ciudades del valle del Guadalquivir, con todos sus términos, posesiones y alquerías dependientes, germen del futuro alfoz de las ciudades. Posteriormente fue Muhāmmad alAhmar, primer rey nașrí de Granada, el que entablaría contactos con el rey castellano y fruto de ellos fue la toma de Arjona y el pacto para la entrega de Jaén, otras dos ciudades del valle, entregadas en los mismos términos que las anteriores; sólo la ciudad de Ubeda fue conquistada sin que se mencione su pertenencia u obediencia a algún rey musulmán. $Y$ casos similares son también los de Córdoba y Sevilla: conquistadas las ciudades, caen en poder castellano las campiñas dependientes de ellas. Por el contrario cuando se refiere a la incorporación de los territorios serranos las referencias documentales no mencionan para nada su pertenencia $u$ obediencia a nadie ajeno al mismo terreno. En los documentos y noticias diversas conservados sólo se hace referencia al hecho de que el rey castellano había estipulado con los habitantes de estos territorios una ciertas convenientias, una capitulación (QUESADA 1987: pp. 521-528), sin que se cite en ningún momento algún tipo de dependencia urbana de los mismos.

Por lo que se puede inferir, la conquista de las ciudades del valle es independiente de la de los territorios serranos. Probablemente debido a la ausencia de fuertes lazos entre unas y otros, las formas de conquista fueron diferentes y los resultados también: en las antiguas madinas musulmanas se constituyen concejos dotados de alfoces más o menos amplios, según, en la mayoría de los casos, la extensión del anterior distrito urbano islámico; mientras que las tierras alejadas de las ciudades son entregadas a diversos señores, suponiendo en muchas ocasiones el germen de futuros señoríos. Estas dos fórmulas de organización de las tierras conquistadas, creación de concejos dotados de fueros y la cesión directa a diversos nobles castellanos, parecen basarse en una diferencia entre antiguos distritos urbanos islámicos y las tierras de montaña, organizadas según otros patrones distintos y ajenos a la organización urbana.

Hay a este respecto un dato que puede ser revelador de la dificultad de controlar la montaña desde las ciudades del valle. Cuando en I 243 Fernando III cede al concejo de Baeza los castillos y territorios situados en el curso alto del río Jandulilla -que sólo habían sido conquistados parcialmente-, lo hace con la salvaguarda de que han de quedar en poder del señor de Jódar hasta su muerte, y sólo en ese momento se integrarían efectivamente en la jurisdicción de la ciu$\mathrm{dad}^{15}$. ¿Por qué este período transitorio?. ¿Se puede considerar como una merced la cesión de unos territorios aún sin conquistar para, una vez conquistados y normalizados, devolverlos a la jurisdicción urbana?. Creemos que no. Al contrario, bien pudo suceder que fuese imposible la integración de estas tierras desde la ciudad de Baeza porque Muhāmmad al-Baŷyasí no controlase políticamente la sierra. De ahí la necesidad de buscar un método específico para su incorporación, previéndose que una vez conseguido el objetivo, los territorios pasasen a depender del concejo baezano. Es ésta, la relación entre las ciudades del valle y los hussūn y sus alquerías de la montaña en el período inmediatamente anterior a la conquista castellana, una cuestión aún poco estudiada, por lo que no es posible generalizar desde este caso particular, que,

15 Documento del 6 de abril de 1243, publ. por HIGUERAS 1974: pp. 22-24. 
no obstante, apunta hacia la idea de la existencia de importantes diferencias entre el valle del Guadalquivir, donde la ciudad es el elemento preponderante, y las sierras, un mundo eminentemente rural.

\section{LAS CONQUISTAS DEL SIGLO XIII: RUPTURA DEL MODELO ANTERIOR Y CONFIGURACIÓN DE UNO NUEVO}

Este modelo de poblamiento andalusí vigente al menos desde el siglo XI entra en crisis en el siglo XIII como consecuencia aquí de la actuación de los castellanos. El proceso de conquista del territorio llevó consigo inevitablemente una carga de violencia y destrucción que puso fin a muchas de las comunidades rurales que acabamos de ver. Los asaltos a castillos y poblados, los saqueos, los incendios de cosechas, alquerías y arrabales, cautiverios y emigraciones forzadas de poblaciones enteras jalonan los itinerarios de la conquista castellana descritos en las crónicas de la época.

No obstante, la conquista militar no arrasó el territorio y una vez consolidadas las posiciones fue necesario reorganizar el poblamiento sobre nuevas bases, aunque contando necesariamente con la población vencida. En las ciudades del valle del Guadalquivir el sistema seguido fue el de la expulsión de la población musulmana de los recintos urbanos y su reubicación en los núcleos rurales dependientes de la misma. Una vez vacía la ciudad de sus primitivos habitantes, son asentados en ella pobladores cristianos venidos de otros lugares de la corona de Castilla esencialmente. A estos repobladores se les proporcionan casas en la ciudad y tierras de labor en su término en una cantidad variable reproduciendo, si bien amortiguadas, sus diferencias sociales de origen. Es decir, desde un primer momento se instala en las ciudades andaluzas un sistema de poder jerarquizado, organizado en torno a un concejo en el que los caballeros acabarán convirtiéndose en una oligarquía monopolizadora del poder. A estos concejos urbanos se les va a dotar de un territorio, un alfoz, sobre el que ejercerán su jurisdicción, que corresponde generalmente al mismo que en el período anterior se organizaba en torno a la madina islámica. Gracias a este mecanismo, en cuyos detalles no podemos extendernos, se logró el sometimiento efectivo del entorno rural de las ciudades.

Este sistema, como hemos visto, no pudo ser aplicado, en cambio en las tierras marginales, cuyas relaciones con las ciudades eran más débiles y que contaban, presumiblemente, con una organización interna bastante autónoma. En este caso se hubo de arbitrar algunas variantes para conseguir su efectiva sumisión. En el valle del río Jandulilla, que nos viene sirviendo de ejemplo, se cita en varias ocasiones, como ya hemos mencionado, la existencia de unos pactos acordados por Fernando III y los moros de los castillos de Cabra, Neblir y Chincóyar. Es de suponer, puesto que no se cita ningún caudillo que estos pactos se establecieron con las aljamas de las tres comunidades que se organizaban en torno a estos ḥușūn, es decir, con unas comunidades libres no supeditadas a las imposiciones de un poder político externo. En líneas generales las convenientias fijadas entre las aljamas musulmanas y el rey castellano, o su representante en la zona, Sancho Martínez, establecen la cesión de los recintos fortificados a los castellanos, el reconocimiento de soberanía por parte musulmana hacia los cristianos y el pago de una serie de tributos, quedando en libertad los musulmanes de abandonar sus tierras y emigrar hacia otras zonas.

Sobre estas bases comienza una etapa nueva, que podríamos denominar de "epigonismo mudéjar", en la que desde el punto de partida que hemos visto comenzará una creciente presión sobre las comunidades mudéjares, similar a la sufrida por las de las campiñas del valle del Guadalquivir: la instalación de campesinos cristianos, incluso en las tierras serranas hacia mediados de siglo, con sus propia concepción y uso del territorio, la inclusión de estas tierras como nuevos pastos invernales en las cañadas ganaderas castellanas, pusieron en marcha un proceso irreversible de transformación del espacio en el que las áreas irrigadas debieron sufrir la presión de 
la ganadería extensiva castellana, que vive un período de expansión al socaire de los avances de la industria lanera, y del cereal, cultivo extendido por los nuevos pobladores, que necesitaba menos mano de obra que la huerta y cuya producción permite el pago de rentas y la acumulación de excedentes de una forma mucho más simple. A ello habría que añadir la creciente feudalización del dominio sobre las comunidades mudéjares que podría quedar reflejada en la creación de una red de parroquias rurales, así en 1255 el obispo de Jaén y Sancho Martínez firman un acuerdo sobre la constitución y reparto de rentas en las parroquias de Solera, Polera, Gris, Alló y Ogáyar, en el que se incluye el "diezmo todo de los moros"1"6; y, por otro lado, en la concepción feudal de las relaciones entre las alquerías pobladas por mudéjares y los castillos dominados por guerreros castellanos, que está claramente reflejado en el problema de la sofra analizado por P. Guichard para la Valencia del siglo XIII y que supuso la evolución de una obligación de carácter público (reparación de murallas, mantenimiento de caminos, etc.) "hacia una corvea agrícola pura y simple" (GUICHARD 1987: p. 219).

La creciente presión sobre las comunidades mudéjares bajo dominio castellano les llevó final e indefectiblemente a no aceptar el rápido proceso de aculturación y sometimiento que venían sufriendo y en 1264 inician una revuelta contra el conquistador, apoyados por los principados musulmanes de Jerez, Niebla, Murcia y Granada y que acabará con la represión de la misma en los territorios conquistados y la marcha generalizada de la población mudéjar hacia estos refugios que, también, uno tras otro fueron cayendo en poder castellano.

De todas las tierras "tributadas" que recibió Alfonso $X$ sólo Granada escapó finalmente a su control. $Y$ en ello se debieron conjugar diversos factores: se ha señalado frecuentemente como causa la orografía del territorio que hacía más dificultosa la realización de campañas militares, a lo que habría que añadir el cambio en la coyuntura de las sociedades feudales, no sólo la castellana, iniciándose la primera gran crisis del feudalismo, que se agravará en el siglo siguiente; y también la aparición en la península de los meriníes, quienes una vez consolidado su poder en el Magrib, comienzan a expandirse por alAndalus como habían hecho sus antecesores almorávides y almohades.

En el último cuarto de siglo asistimos, entonces, a una grave crisis castellana, que a niveles políticos estaría representada por los problemas sucesorios de Alfonso $X$ y las minorías de los herederos de Sancho IV, y a otros niveles con el cierto fracaso de las repoblaciones emprendidas en las décadas anteriores que deja al valle del Guadalquivir claramente subpoblado durante este período (GONZÁLEZ JIMÉNEZ 1985). A ello hay que añadir las acciones militares de los meriníes, siendo ahora los cristianos los que han de sufrir los asaltos, incendios, saqueos y cautiverios que en décadas anteriores habían protagonizado ellos mismos.

Volviendo a la zona de nuestro análisis, vemos cómo a partir de estos años finales del siglo XIII el paisaje comienza a cambiar de forma sustancial.

La práctica totalidad de los yacimientos que hemos visto hasta ahora se abandonan en estas fechas. En todos ellos no hemos encontrado ningún resto nazarí, tanto en los fortificados como en los poblados. Las cerámicas más tardías corresponden a mediados o fines del siglo XIII: algunos esgrafiados, cuerda seca total o estampillados. Claramente el sistema de poblamiento existente hasta entonces, incluido el "epigonismo mudéjar", ha sido abandonado. Intentemos acercarnos a sus causas y mecanismos.

A partir del último cuarto de siglo, tras los sucesos que someramente hemos mencionado, el dominio efectivo de los castellanos se va a circunscribir al valle del Guadalquivir

16 Documento fechado el 26 de agosto de 1255, publ. SEGURA 1976: p. 192. 
abandonándose muchas de las posiciones avanzadas que se habían conseguido a mediados de siglo: los herederos de Sancho Martínez apenas van a controlar ahora el castillo de Jódar y el valle de Bedmar, situado al $\mathrm{N}$ del macizo de Mágina. Por su parte los nazaríes también se encuentran inmersos en una crisis, aunque ésta de signo distinto a la castellana: están en proceso de definición de su propio reino: luchas entre los diversos linajes musulmanes que lo componen, destacando el enfrentamiento entre Nașríes y Ašqilūlas; o la presencia de los meriníes ocupando la zona occidental del reino y sus relaciones con los diversos linajes granadinos. Esta situación nos lleva a considerar que en estos momentos los territorios efectivamente dominados por el reino nazarí se circunscribirían a las Hoyas del surco Intrabético, en cada una de las cuales encontramos sendos linajes o grupos preponderantes, y las costas, esencialmente los puertos de Málaga y Almería y las tierras en torno al Estrecho de Gibraltar.

Las montañas subbéticas debieron quedar en estos momentos de finales del siglo XIII en una situación intermedia entre castellanos y nazaríes, sin que realmente ninguno de ellos ejerciera un control efectivo sobre el territorio. Ni desde el valle del Guadalquivir ni desde el Surco Intrabético se ejerce gran influencia ahora sobre la montaña. Muestra de ello puede ser el caso del alcaide de Tíscar, castillo situado en la sierra de Cazorla, Mahomad, fijo de Handon, quien en 1275 nos aparece como sometido al rey castellano Alfonso $X$ cuando dona éste $y$ otros castillos al concejo de Ubeda ${ }^{17}$ y que en 1319 , por el contrario, ha escapado al control, puesto que el infante don Pedro intenta llegar a un acuerdo con él, como si representase un poder autónomo, a lo que el alcaide de Tíscar se niega. Dice la Gran Crónica de Alfonso XI: "E aquel cavallero moro Mahomad Handon enbio dezir al ynfante don Pedro que bien sabia el en como no obedesçia a moro ni a christiano, e que mas queria el ser libre y sin tributo que non tributario" (CATALÁN 1976: p. 313).
Como bien apunta M. Barceló para el caso de Tíscar, en los años siguientes al retroceso cristiano, a finales del siglo XIII y comienzos del siglo $X I V$, en las sierras debieron pervivir una serie de comunidades (BARCELÓ y otros 1989: p. 17I), herederas de las existentes en el siglo anterior, que debieron proceder a reorganizar el territorio que ocupaban. Finalmente, la ocupación castellana de la Sierra de Cazorla puso fin a estas comunidades.

En nuestro caso, por el contrario, los cristianos abandonaron definitivamente las conquistas en la sierra y se circunscribieron a dominar el valle y sus aledaños, dejando la sierra en manos musulmanas. $Y$ podemos considerar que es ahora cuando se inicia una transformación en profundidad del poblamiento existente hasta entonces.

De la época bajomedieval, siglos XIV y XV, datan una serie de yacimientos bien distintos a los que hemos visto hasta ahora. Esencialmente de este período datan los castillos por antonomasia de la zona: los de Bélmez, Solera y Huelma, así como varias torres cilíndricas de características similares todas ellas (aparejo de mampostería, entrada en alto, etc.). Son, concretamente, tres las torres que se conservan: la torre del Cerro de la Atalaya, al Norte de la Vega de Neblín; la torre del Sol, en las cercanías del castillo de Bélmez; y la torre del Lucero, entre el castillo de Bélmez y el de Huelma, siendo esta última la única que presenta algunas diferencias al estar circundada por un muro semicircular. Aparte de estas tres torres, conocemos otras dos hoy día desaparecidas, pero bien documentadas, situadas al S y SE del castillo de Huelma, la de Fajarrey y la de Gallarín (QUESADA 1989: pp. 214-215).

En estos yacimientos aparece cerámica nazarí, muy escasa evidentemente en las torres, y cristiana, muestra clara de los avatares militares y políticos de la frontera castellano-nazarí. Igualmente en todos ellos hay labores constructivas tanto cristianas como

17 Documento fechado el 25 de junio de 1275 en Beaucaire, publ. GONZÁLEZ 1991: pp. 446-447. 
nazaríes, aunque el grueso de las labores de fortificación parecen corresponder a la iniciativa nazarí, ya que hasta el siglo XV fueron la frontera norte del reino granadino. Es de destacar en este sentido el gran aljibe del castillo de Huelma, construido en un hormigón muy duro de un grosor medio de 1,50 m, y con unas dimensiones de 8,30 por 3,25, y una profundidad hasta el arranque de la bóveda de 1,65 m., lo que supone una capacidad de $44,5 \mathrm{~m} 3$, con una técnica que recuerda por sus semejanzas a otros similares del recinto de la Alhambra'18, lo que nos daría una cronología de la primera mitad del siglo XIV, bastante ajustada con el momento que analizamos.

Como vemos, todos los yacimientos que hemos referido con materiales adscribibles al período nazarí son castillos y torres. Frente a ellos, hay una ausencia prácticamente total de yacimientos sin fortificar. Solo hemos detectado uno. Se trata del denominado "Cueva del Moro", situado en las inmediaciones de la Torre del Cerro de la Atalaya, al Norte de Neblín. En este yacimiento, sin restos constructivos visibles, ha aparecido cerámica claramente nazarí, decorada en azul cobalto, probablemente del siglo XV.

Como características comunes de estos castillos podemos destacar la presencia, además de los aljibes, de un doble recinto murado, ausente totalmente en los husụūn del período anterior, de una extensión considerable, haciendo que el perímetro fortificado sea claramente superior al de un simple castillo, especialmente los dos más importantes y representativos de este período, los de Huelma y Bélmez.

Los restos que hoy día se conservan nos hace pensar que estos yacimientos son algo más que meros castillos, algo que también pensaban los cronistas del siglo $\mathrm{XV}$, que se refieren a ellos generalmente como "villas", trascendiendo con esta denominación la de simple castillo, mientras que aún a principios del siglo XIV no se aprecia esta diferencia. Así cuando en 1316 el infante don Pedro conquista Bélmez la Gran Crónica de Alfonso XI dice simplemente: "E acabo de veynte e vn dias que el ynfante don Pedro llego a aquel castillo, a tan afincados fueron los moros que dentro estauan, que le ovieron de dar el lugar" (CATALÁN 1976: p. 303). Mientras que un siglo después, cuando de nuevo los castellanos realizan conquistas en estas tierras, los relatos de las crónicas dejan constancia de las diferencias. Así en 1438 cuando se conquista Huelma en la Crónica del Halconero podemos leer: "A 21 dias de abril tomó Yñigo Lopez de Mendoça, por fuerça de armas, a Huelma, vna villa de moros... E el castillo de Huelma se detubo ciertos dias despues que la villa fue tomada, e al fin fue entrado" (CARRILLO 1946: p. 252). Y similar es el caso de Bélmez cuando es conquistado en I448: "Ganose este lugar y castillo de Belmez a los moros en el año de 1448 por los veçinos de Baeça, cuyo capitan fue en esta conquista Fernando de Villafañe" (XIMENA, JURADO 1991: p. 186).

Entre el relato de 1316 y los del siglo XV hay algunas diferencias. Mientras en el primero sólo se hace referencia a un recinto fortificado, en los otros dos se habla claramente de forma diferenciada de la "villa" o "lugar" y del "castillo", siendo, por tanto, dos los espacios conquistados: primero un recinto civil fortificado, la villa, y después el castillo, que podríamos considerar como una pequeña alcazaba.

Entre estas dos fechas, por tanto, el "casti"lo rural", elemento director del poblamiento en la etapa anterior, como hemos visto, ha desaparecido y ha sido sustituido por otro tipo de fortificación. Ahora el castillo no es sólo refugio ocasional o sede de una pequeña guarnición, sino el elemento aglutinador del poblamiento, no sólo políticamente, sino también, y ésta es la diferencia, físicamente. Las transformaciones del poblamiento en este sentido no son específicas de esta área, sino que son generales en todo el reino nașrí: así

18 Concretamente nos referimos al Albercón de las Damas que hay sobre el Generalife, punto de recogida de las aguas que llegan a la Alhambra a través de las acequias Real y del Tercio y el Albercón del Cerro del Sol, también en la colina de la Alhambra de Granada, MALPICA CUELLO, A.: "El complejo hidráulico de los Albercones", Cuadernos de la Alhambra XXVII (I99I) 65-I0I. 
en otra área montañosa, la Alpujarra, asistimos en estos mismos momentos también a la aparición de las țāca/s desde los aŷzā' preexistentes (CRESSIER 1984), abandonándose los antiguos hușūn, siendo sustituidos por otras fortificaciones nuevas en nuevos emplazamientos y con distintas funciones (MALPICA 1986).

Hemos de imaginar que tras los avatares del siglo XIII (conquistas cristianas, sublevación mudéjar, razzias benimerines, etc.) el poblamiento del valle del Jandulilla debió quedar muy mermado y disperso. Una vez que los castellanos abandonaron la montaña en el último cuarto del siglo, debió comenzar un proceso de reorganización del territorio que, desde luego, no podía simplemente reducirse a una vuelta al pasado.

Si nos detenemos a considerar los yacimientos nazaríes existentes en nuestra zona de estudio podremos ver cómo el poblamiento ha cambiado radicalmente. La Vega de Neblín, uno de los ejes articuladores del poblamiento hasta este momento, queda completamente desierta; sólo en su extremo $\mathrm{N}$, allí donde el valle del Jandulilla se abre al del Guadalquivir, se construye una atalaya de vigilancia; y en sus cercanías se encuentra la llamada "Cueva del Moro", probablemente un simple refugio ocasional; y al SW, pegado ya a la sierra, el castillo de Bélmez y sus dos torres de vigilancia: las del Lucero y la del Sol. Tres torres en total que son simples puntos fortificados adelantados relacionados con la organización defensiva territorio, sin que guarden ninguna relación con el poblamiento de la zona. Y eso es todo. Una zona densamente poblada desde la Antigüedad ahora está prácticamente despoblada.

Y en la vega de Cabrita-Huelma la situación es parecida: abandono total de los asentamientos anteriores y la aparición de dos castillos en sus márgenes: Huelma en su extremo SW, cercano a la sierra también; y Solera, al E.
El cambio en el modelo de poblamiento es evidente: de un poblamiento disperso basado en alquerías que gravitan en torno a un hișn hemos pasado a otro concentrado en el que el poblamiento se organiza alrededor de recintos fortificados mucho más complejos que simples castillos. Se componen de una fortificación en el lugar más prominente, que es a la que las crónicas castellanas Ilaman explícitamente "castillo"; y otra zona situada en las inmediaciones de esta fortificación compuesta esencialmente por casas. En este sentido es taxativa la declaración de un vecino de Huelma, Día Sánchez de la Trinidad, el 28 de febrero de 1566, cuando dice: "...en esta dicha villa de Huelma a abido e ay muros de la villa e castillo e fortaleça e torres en ella e casas e dos puertas de la villa muy antiguas... e dentro de estas dichas dos puertas ay muchas casas y edifiçios de casas caydas muy antiguas e la çerca e muros e puertas susodichas muy antiguas que se caen de viejo..."'.

Las características de la población que vivía en estas "villas" fortificadas apenas son conocidas. En general, el mundo rural sufrió grandes transformaciones desde la época andalusí a la nazarí. Según los estudios realizados en la zona costera granadina se produjo un deterioro de las antiguas comunidades agrícolas, convirtiéndose en práctica habitual la concentración de riqueza, la exogamia y la posesión de tierras en diversas alquerías, que fueron provocando progresivamente la ruptura de la comunidad en la alquería (MALPICA 1984); y con la aparición de personajes con una posición social preeminente sobre el resto, tales como los alguaciles, que se suceden en auténticas dinastías (MALPICA 198283: pp. 192-193).

En las zonas fronterizas suponemos que debió pasar algo similar. La desaparición de los hușūn y sus alquerías a finales del siglo XIII dio paso a un nuevo sistema de poblamiento en el que los restos de las poblaciones existentes hasta entonces en la montañaa se debieron de reagrupar mediante unos meca-

19 Archivo de la Real Chancillería de Granada, cab. 3, leg. 322, pieza n I-IX, fol. 29. 
nismos prácticamente desconocidos, bien mediante la aglutinación en torno a caudillos como parece ser el caso de Muhāmmad Handum en Tíscar (BARCELÓ y otros 1989) o bien en torno al emergente poder de los nazaríes, quienes una vez consolidados en Granada y las zonas centrales del reino comenzarán a sistematizar su dominio sobre las zonas que hasta entonces sólo teóricamente dependían de ellos.

Las modalidades empleadas en este proceso nos son también desconocidas. Habría que pensar, quizás, en la consecución de diversos pactos entre el sultán granadino y estos núcleos dispersos en las montañas que se concretarían en la construcción de los nuevos castillos y villas fortificadas que hemos visto que surgen en estos momentos como nuevo modelo de poblamiento, que si bien aseguraba la presencia del poder del sultán a lo largo de toda la frontera no llegó a anular la autonomía de funcionamiento de estas comunidades con respecto a los alcaides instalados en lo que podríamos denominar pequeñas alcazabas de estas "villas". Así en Zagra, fortaleza fronteriza entre Loja y Priego de Córdoba, el alcaide no sólo no tenía jurisdicción sobre la población aneja al castillo, o sobre sus campos cultivados en este caso, sino que ni siquiera poseía un ápice de tierra en el término de la misma, reduciéndose su autoridad estrictamente al circuito del castillo (MALPICA 1989).

Son, por lo tanto, unas nuevas formas de poblamiento y de relación con el poder central que tienen también su correlato en la organización del espacio. Ahora estos núcleos agrupados de población, que con todas las reservas necesarias podríamos considerar como pequeñas madinas, abandonan las áreas de vega, donde tradicionalmente se había concentrado el poblamiento y se opta por otros emplazamientos más elevados, en los que, ante la desaparición de las alquerías del valle, las necesidades de la defensa fronteriza prevalecen.

20 Archivo Municipal de Jaén, leg. 220
Este cambio debió suponer sin duda alguna la desaparición de las tradicionales áreas irrigadas que debieron existir en la etapa anterior y que ya durante el siglo XIII se habían visto constreñidas e invadidas por la presencia castellana. No obstante, el abandono de la vegas y sus áreas de cultivo no supuso como en las tierras conquistadas por los castellanos la dedicación preferente a las cabalgadas de robo y saqueo protagonizadas por los caballeros feudales, sino que las comunidades que pasaron a vivir en estos castillos continuaron desarrollando sus actividades productivas, objeto en numerosas ocasiones de la rapiña de los caballeros del otro lado de la frontera, cuyos robos de ganado y personas, quemas de cosechas y tala de árboles pueblan las crónicas bajomedievales, muestra inequívoca de la continuidad productiva de las poblaciones de la frontera nazarí. De lo que quedan indudables pruebas documentales. Así cuando, por ejemplo, se emprende la repoblación de Huelma en 1495, si bien una parte de la tierra son rozas para desmontar, otra, la más cercana a la población, es ya tierras cultivada; y similarmente cuando en 1485 se conquista Cambil, al SE de Mágina, los Reyes Católicos donan a su secretario Francisco de Madrid una tierra ya en cultivo, el heredamiento de Bornos "donde labraua Abrahen de Tarax e otros moros sus conpañeros ... con todos sus terminos, tierras y labranzas y pastos e aguas dulzes e saladas, estantes e manantes, e con esto me fizieron mas merzed de la guerta que fue de Ali Canbili... con las hazas, tierras y morales que el dicho Cambili tenia en el dicho termino de Canbil e Alhauar e con todos los otros morales que estan en el dicho termino..."

En definitiva, tras la crisis y transformaciones del siglo XIII, se genera un nuevo modelo de poblamiento en el que la situación fronteriza de las montañas subbéticas va a tener cierta importancia, aunque los cambios sean generales en todo el reino de Granada. En el caso concreto que nos ocupa podemos avanzar como algunas de sus características específicas en primer lugar la propia pervivencia de 
las comunidades campesinas en las zonas fronterizas, que conservan aún su libertad y autonomía de funcionamiento respecto al poder central, representado por los alcaides de los castillos, al contrario que en la frontera castellana, donde el vacío demográfico y el proceso de feudalización son ya bien patentes a inicios del siglo XIV, predominando aquí las mesnadas militares.

Y en segundo lugar, la gran diferencia con el modelo de ocupación del espacio de la etapa andalusí, la sustitución de un hábitat disperso de alquerías relacionadas con hușūn localizado preferentemente en las áreas agrícolas más productivas, las vegas, por otro concentrado y fortificado que reúne en un mismo emplazamiento a la población superviviente de las antiguas alquerías y las guarniciones militares granadinas. $Y$ estos nuevos emplazamientos abandonan como lugar de ubicación las áreas bajas de vega por otros situados en puntos más elevados, en los que las necesidades defensivas quedan mejor atendidas.

Sobre esta base se desarrolló en los siglos XIV y XV un modelo de poblamiento específicamente nazarí que si bien recoge las tradiciones anteriores tiene ya poco que ver con el andalusí. Durante el siglo XIII se han producido una serie de transformaciones en profundidad en el poblamiento rural de montaña, aunque no sólo en él, que si bien hemos podido describir a grandes rasgos, nos son aún desconocidas en gran parte.

\section{BIBLIOGRAFÍA}

ACIÉN, M. (1993): "La cultura material de época emiral en el Sur de al-Andalus. Nuevas perspectivas", I Encuentro sobre Arqueología y Patrimonio, Salobreña, 1993

ACIÉN, M. (1994): Entre el feudalismo y el Islam. Umar Ibn Hafșūn en los historiadores, en las fuentes y en la historia, Jaén.

AGUIRRE, F.J:; JIMÉNEZ, Ma C. (1979): Introducción al Jaén islámico, Jaén.

BARCELÓ, M. y otros (1986): Les aigues cercades (Els «qanāt(s)» de l'illa de Mallorca), Palma de Mallorca.

BARCELÓ, M. y otros (1988): Arqueología medieval. En las afueras del medievalismo, Barcelona.
BARCELÓ, M, KIRCHNER, R.; MARTÍ, R.; TORRES, J.M. (1989): "Sistema de regadío y asentamientos andalusíes en la estribación Sur de la Sierra de Cazorla". I coloquio de Historia y Medio Físico. El agua en zonas áridas. Almería, pp. $169-182$.

BAZZANA, A.; CRESSIER, P.; GUICHARD, P. (1988) Les châteaux ruraux d'al-Andalus. Histoire et archéologie des hușūn du sud-est de l'Espagne, Madrid.

CARRILLO DE HUETE, P. (1946): Crónica del Halconero de Juan II, ed. J.M. Carriazo, Colección de Crónicas Españolas VII, Madrid.

CATALÁN, D. (ed.)(1976): Gran Crónica de Alfonso XI, ed. de D. Catalán, Madrid.

CRESSIER, P. (1984): "Le château et la division territorial dans l'Alpujarra médiévale: du hiṣn à la țā‘a», Mélanges de la Casa de Velazquez XX, pp. II5-144

GARCÍA GÓMEZ, E.; LEVI-PROVENÇAL, E. (1980): El siglo XI en primera persona. Memorias' de 'Abd Allāh, último rey zirí de Granada, destronado por los almorávides (1090). Madrid.

GONZÁLEZ JIMÉNEZ, M. (1985): "Andalucía Bética", en GARCIA DE CORTÁZAR, J.A. y otros: Organización social del espacio en la España medieval. La Corona de Castilla en los siglos VIII a XV, Barcelona, pp. 163-194.

GÓNZALEZ JIMÉNEZ, M. (ed.) (|99|): Diplomatario andaluz de Alfonso $X$, Sevilla.

GUICHARD, P. (1987): "El problema de la sofra en el reino de Valencia en el siglo XIIl», Awraq II (1979), pp. 64-7I; reeditado en Estudios sobre historia medieval, Valencia, pp. 205- 219.

HIGUERAS, J. (1974): Documentos latinos del siglo XIII al XVII en los archivos de Baeza (Jaén). Transcripción, traducción y comentario lingüístico, Jaén.

IBN HAYYĀN (|98|): Crónica del califa 'Abdrrahmān III an-Nàșir entre los años 912 y 942 (al-Muqtabis V), trad. de $M^{a}$ J. Viguera y F. Corriente, Zaragoza.

JIMÉNEZ SÁNCHEZ, M; QUESADA, T. (1992): "En los confines de la conquista castellana: toponimia y poblamiento de los montes granadino-giennenses en el siglo XIII según la documentación cristiana". Revista del Centro de Estudios Históricos de Granada y su Reino, $2^{\mathrm{a}}$ época, n6, pp. 5।-80

LAGARDÈRE, V. (1993): Campagnes et paysans d'alAndalus (VIII $-X V^{e}$ s.). , Paris.

LEVI-PROVENÇAL, E.; GARCÍA GÓMEZ, E. (1950): Una crónica anónima de 'Abd al-Rahmmān III al-Nāșir. MadridGranada.

LÓPEZ, T. (1787): Mapa Geográfico del Reyno de Jaén dividido en los Partidos de Jaén, Baeza, Úbeda, Andújar, Martos y las poblaciones de Sierra Morena, por don - Madrid. 
MADOZ, P. (1988): Diccionario Geográfico-EstadísticoHistórico de España y sus posesiones de Ultramar, Madrid, |845-|850, sub voce «Jaén, prov.», reimp. facsímil ed. Ámbito, vol. Jaén, Salamanca.

MALPICA, A. (1982-83): "La villa de Motril y la repoblación de la costa de Granada (I 489-I5 I0)", Cuadernos de Estudios Medievales X-XI, pp. 169-193.

MALPICA, A. (1984): Turillas, alquería del alfoz sexitano, Granada.

MALPICA, A. (1986): "Castillos y sistemas defensivos en las tāacas de Sāhil y Suhayl: un análisis histórico y arqueológico", Actas del I Congreso de Arqueología Medieval Española, Zaragoza, pp. 357-380.

MALPICA, A. (1989): "El castillo de Zagra y el alfoz de Loja a fines de la Edad Media" Homenaje al prof. Juan Torres Fontes, Murcia, pp. 959-973.

MALPICA, A. (|99|): "El complejo hidráulico de los Albercones", Cuadernos de la Alhambra XXVII, pp. 65IOI.

NAVARRETE, Ma S. CARRASCO, J. (1978): "Neolítico en la provincia de Jaén", Cuadernos de Prehistoria de la Universidad de Granada Vol. III, pp. 62-64

OLMO, L. (1992): "El reino visigodo de Toledo y los territorios bizantinos. Datos sobre la heterogeneidad de la Península Ibérica" Coloquio hispano-italiano de Arqueología Medieval, Granada, pp. 185-198

PIEL, J.M. (1949-1950): "Os nomes dos santos tradicionais hispânicos na toponimia peninsular", Biblos XXV, pp. 287-353 y XXVI, pp. 28|-3|4.

QUESADA, T. (1987): "Los pactos de sumisión de los mudéjares de la Serranía de Mágina (Jaén) y su significado ecocómico". Actas del IV Simposio Internacional de Mudejarismo: Economía, Teruel, pp. 521-528.
QUESADA, T. (1989): La serranía de Mágina en la Baja Edad Media, Granada.

QUESADA, T. (1991): "El poblamiento medieval en las sierras subbéticas de Jaén y Granada. El caso de Sierra Mágina" Studia Historica. Historia Medieval IX, pp. I59-I8I.

QUESADA, T. (ep.) "Las transformaciones del poblamiento rural islámico durante el siglo XIII. Las montañas subbéticas y los orígenes del reino nașrí de Granada". IV Encuentro de Arqueología y Patrimonio (Salobreña 1993)

QUESADA, T.; MOTOS, E. (Ep.I) "Informe de la campaña de prospección", Anuario Arqueológico de Andalucía/ 199

QUESADA, T.; MOTOS, E. (Ep.2) "Informe de la campaña de prospección". Anuario Arqueológico de Andalucíal 1992

QUESADA, T.; MOTOS, E. (Ep.3) "Informe de la campaña de prospección", Anuario Arqueológico de Andalucíal 1993

SECO DE LUCENA, L. (1974): Topónimos árabes identificados, Granada, 1974.

SEGURA MORENO, M. (1976): Estudio del Códice Gótico (siglo XIII) de la Catedral de Jaén, Jaén.

TERES, E. (1972): «'An-Nāẓūr', 'Al-Manzar' y 'An-Naẓra' en la toponimia hispanoárabe», Al-Andalus $X X X V I I$, pp. 325-335.

WICKHAM, Ch. (1984): "The other transition. From Ancient Word to Feudalism", Past and Present n ${ }^{\circ} 103$, pp. 3-36.

XIMENA JURADO, M. (199|): Catálogo de los obispos de la iglesias catedrales de Jaén y anales eclesiásticos de este obispado, (Jaén, 1654) (ed. facsímil) Granada. 


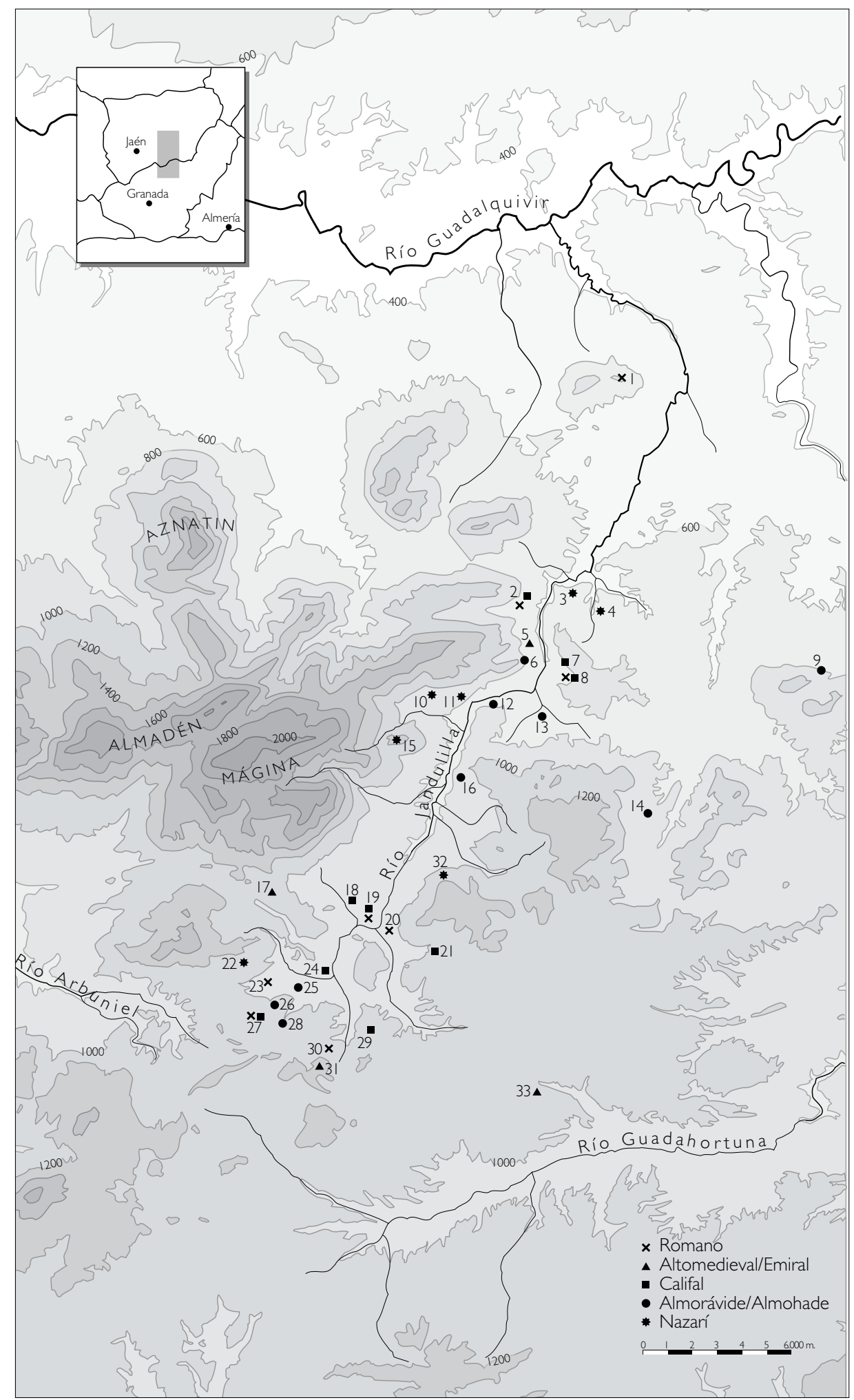

Mapa del poblamiento.

1. Fontanarejo 2. Barranco de las Majadas 3. Torre del Cerro de la Atalaya 4. Cueva del Moro 5. Barranco de los Hornillos Bajos 6. Castil de la Sierra de la Cruz 7. Cuevas de Neblín 8. Barranco de Rincón 9. Castillejo del Tejar de los Moros 10. Castillo de Bélmez 11. Torre del Sol 12. Cerro Atalaya 13. Castillejo de Neblín 14. Castillejo del Cerro S. Juan 15. Torre del Lucero 16. Castillejo del Barranco de Aguas Amarguillas 17. Castellón de la Cañada del Acero 18. Cortijo de la Castellanía 19. Cortijo Pajarillo 20. Sótar 21. Cortijo de los Nacimientos 22. Castillo de Huelma 23. Cerrillo de las Rojas 24. Cortijo de las Piedras 25. Cortijo Manzanares 26. Cerro de la Encina 27. Fuente de la Peña 28. Castillazo de Ruicerezo 29. Cortijo de las Casas 30. Cantaruelas 31. Cerro Gonzalo 32. Castillo de Solera 33. Dientes de la Vieja 